
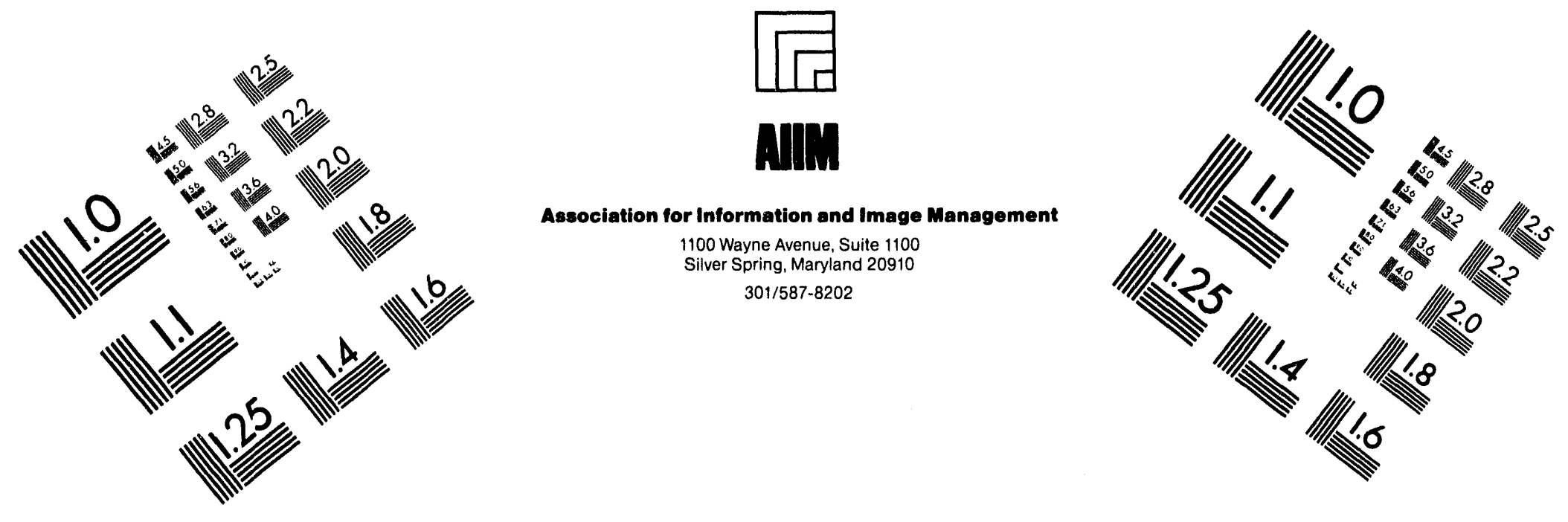

\title{
Centimeter
}

$\begin{array}{llllllllllllllll}1 & 2 & 3 & 4 & 5 & 6 & 7 & 8 & 9 & 10 & 11 & 12 & 13 & 14 & 15 & \mathrm{~mm}\end{array}$

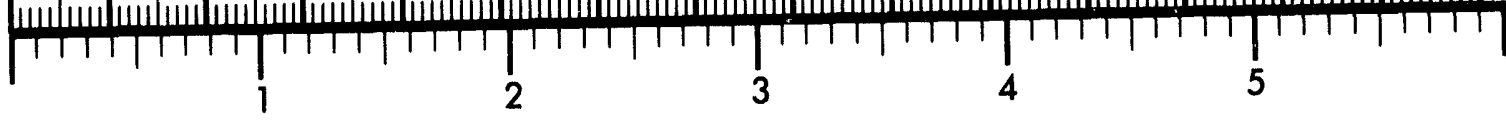
Inches
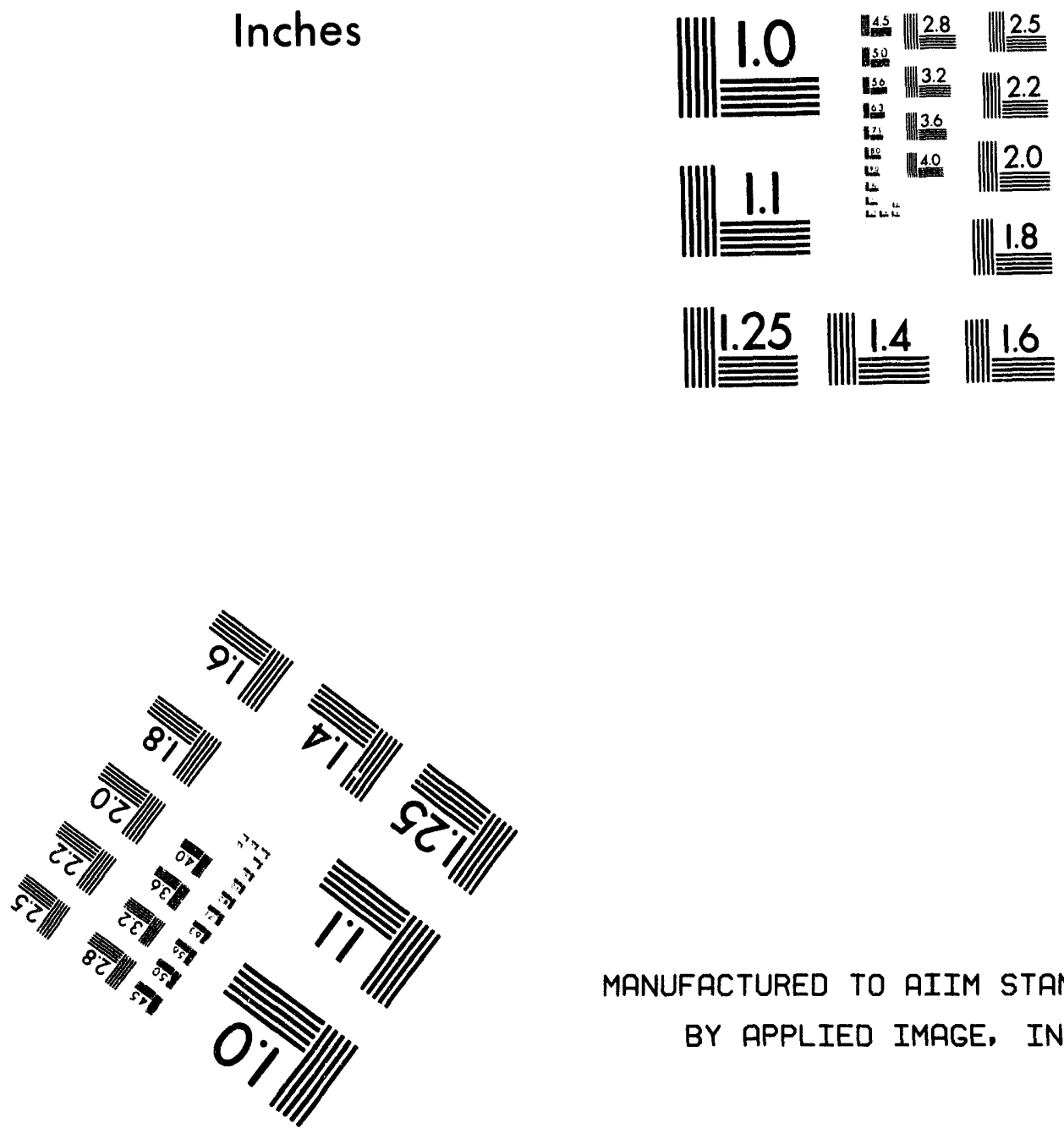

MANUFACTURED TO AIIM STANDARDS BY APPLIED IMAGE, INC.

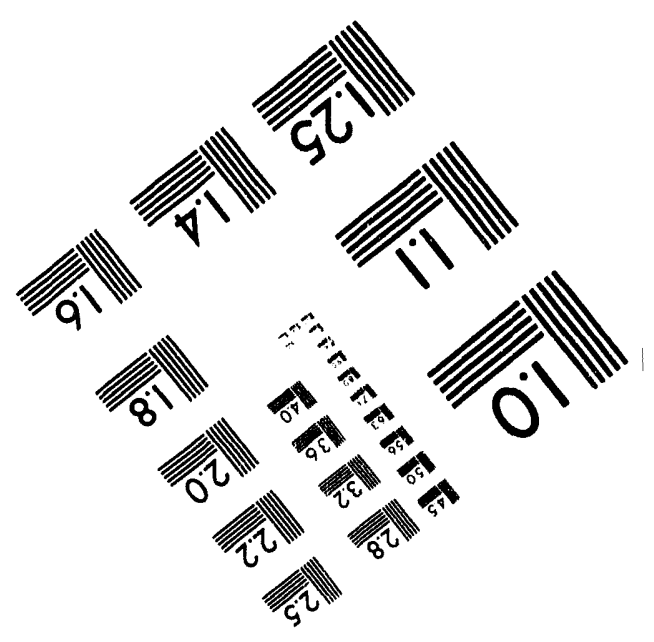



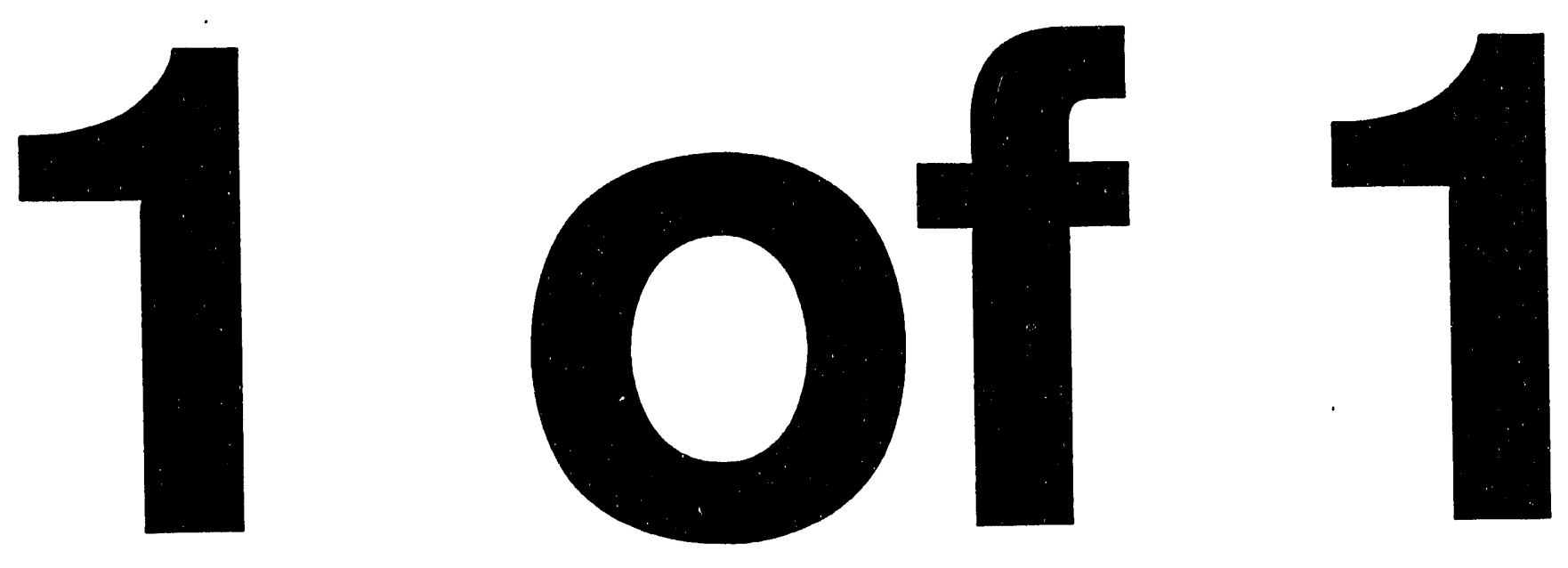


\title{
ANK/CMT/CP-.79852 Cove $931108-56$
}

\section{GENERATION OF VOLATILE ORGANIC COMPOUNDS BY ALPHA PARTICLE DEGRADATION OF WIPP PLASTIC AND RUBBER MATERIAL *}

by

\author{
Donald T. Reed \\ Argonne National Laboratory \\ Argonne, Illinois 60439 \\ and \\ Martin A. Molecke \\ Sandia National Laboratories \\ Albuquerque, NM 87185-1341
}

The submitted manuscript has been authored
by a contractor of the U.S. Government
under contract No. W-31-109-ENG-38.
Accordinglv, the U. S. Government retains a
nonexclusive, royalty-free license to publish
or reproduce the published form of this
contribution, or allow others to do so, for
$U$.S. Government purposes.

* Work supported by the U.S. Department of Energy, under contracts W31-109-ENG-38.

\section{MASTER}

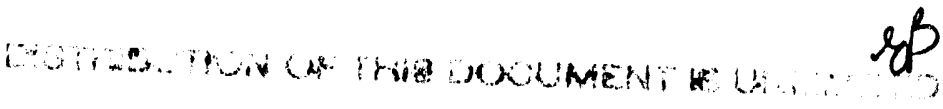




\title{
GENERATION OF VOLATILE ORGANIC COMPOUNDS BY ALPHA PARTICLE DEGRADATION OF WIPP PLASTIC AND RUBBER MATERIAL
}

\author{
DONALD T. REED* AND MARTIN A. MOLECKE** \\ *Donald T. Reed, Argonne National Laboratory, Argonne, IL 60439. \\ **Martin A. Molecke, Sandia National Laboratories, Albuquerque, NM 87185-1341.
}

\begin{abstract}
The generation of volatile organic compounds (VOCs), hydrogen, and carbon oxides due to alpha particle irradiation of polyethylene, polyvinylchloride, hypalon, and neoprene, is being investigated. A wide diversity of VOCs was found including alkenes, alkanes, alcohols, ketones, benzene derivatives, and nitro compounds. Their yields however, were quite low. The relative amounts of these compounds depended on the material, atmosphere present, and the absorbed dose. This investigation will help evaluate the effect of ionizing radiation on the long-term performance assessment and regulatory compliance issues related to the Waste Isolation Pilot Plant (WIPP).
\end{abstract}

\section{INTRODUCTION}

The generation of hydrogen, carbon oxides, and volatile organic compounds (VOCs) due to alpha particle irradiation of plastic and rubber waste materials is being investigated in the Waste Isolation Pilot Plant (WIPP). This study is part of an ongoing effort to evaluate the effects of ionizing radiation for assessing the long-term performance and regulatory compliance issues relevant to the WIPP ${ }^{1,2}$. The formation of VOCs is of interest for two reasons. First, these organics can contribute to gas production both directly, and indirectly by facilitating microbial degradation. Second, since some of the VOCs generated are RCRA-listed organics, their presence may be important in assessing regulatory compliance.

The transuranics are the source of ionizing radiation in transuranic-containing (TRU) waste. The most important isotopes are $\mathrm{Pu}-239$ (average of $\leq 10 \mathrm{~g}$ per waste drum) and $\mathrm{Am}-241$. They undergo alpha decay that provides both a high-energy alpha particle and a recoil nucleus of equal momentum, as high linear energy transfer (LET) particles. These particles interact with a thin surface layer of the organic materials present in a large fraction of WIPP TRU wastes. Previously ${ }^{3}$, we have shown that VOCs are generated radiolytically via a coupled radiolyticthermal process.

Herein, we report the initial results of ongoing experiments to evaluate the nature and extent of radiolytic formation of VOCs under experimental conditions relevant to the long-term environmental conditions of the WIPP. Four materials, polyethylene, polyvinylchloride, neoprene and hypalon, were irradiated with $\sim 4.8 \mathrm{MeV}$ alpha particles. This was done in an air or nitrogen environment at $30^{\circ} \mathrm{C}$. These tests are currently being expanded to include a hydrogen/carbon dioxide atmosphere to support a larger matrix to investigate the effects of ionizing radiation on the biodegradability of irradiated plastic and rubber materials. All of these radiolysis and biodegradability laboratory studies are part of the WIPP Gas Generation Program, as directed by Sandi $\curvearrowright$ National Laboratories (SNL). 


\section{EXPERIMENTAL}

We included two plastic materials, polyethylene and polyvinylchloride, and two rubber materials, hypalon and neoprene, in our test matrix. All of these materials, except for polyethylene, had chlorine as a key constituent. The polyethylene and polyvinyl chloride plastics came from the Rocky Flats tlant and are typical of plastics used in packaging TRU waste. The hypalon and neoprene samples were obtained at Argonne and are typical of the glove materials utilized in glovebox and radioactive waste cleanup operations. These materials were stored at room temperature, in air, and in the dark, prior to use.

The plastic and rubber materials were cut into $6-\mathrm{cm} \times 6-\mathrm{cm}$ squares and mounted $3 \mathrm{~mm}$ from an alpha particle source $\left(238 \mathrm{mCi} / \mathrm{cm}^{2} \mathrm{Am}-241\right.$ with a gold surface coating). The energy deposition rate of the Am-241 foil was established by exposing the Am foil to ethylene gas ${ }^{4}$ and measuring the buildup of hydrogen $\left(\mathrm{G}\left[\mathrm{H}_{2}\right]=1.35 \mathrm{molec} / 100 \mathrm{eV}\right)$. The energy deposition rate measured for these foils was $1.0 \pm 0.1 \times 10^{12} \mathrm{MeV} / \mathrm{h}$.

The foil-plastic assembly and the Teflon-glass irradiation vessel utilized are shown in Figure 1. The plastic-foil configuration was placed in the irradiation vessel, which was sealed, leakchecked, attached to a vacuum manifold, and evacuated to $<10$ mtorr for 3 days before adding the gas phase of interest. Experiments were conducted in either an air or nitrogen atmosphere. Water, as water vapor, was added to establish a relative humidity of about $70 \%$ in the tests.

Once prepared, the vessels were placed in $30^{\circ} \mathrm{C}$ incubators and periodically removed to sample the gas phase. Gas analyses were performed on either a Varian model 3300 or 3400. Hydrogen analyses were performed using argon as the carrier gas with a thermal conductivity detector. Oxygen, nitrogen, and carbon dioxide were determined using a thermal conductivity detector with helium as the carrier gas. Trace organic composition was determined by gas chromatography using a flame ioniration detector (GC-FID) with helium as the carrier gas. For the three chloride-containing materials, a vessel rinse was made after test termination and analyzed for chloride content using ion chromatography. At the end of the experiment, the gas phase was also analyzed by gas chromatography-mass spectrometry (GC-MS) to more fully establish the nature of the VOCs present. The materials used were weighed before and after irradiation to determine weight change.

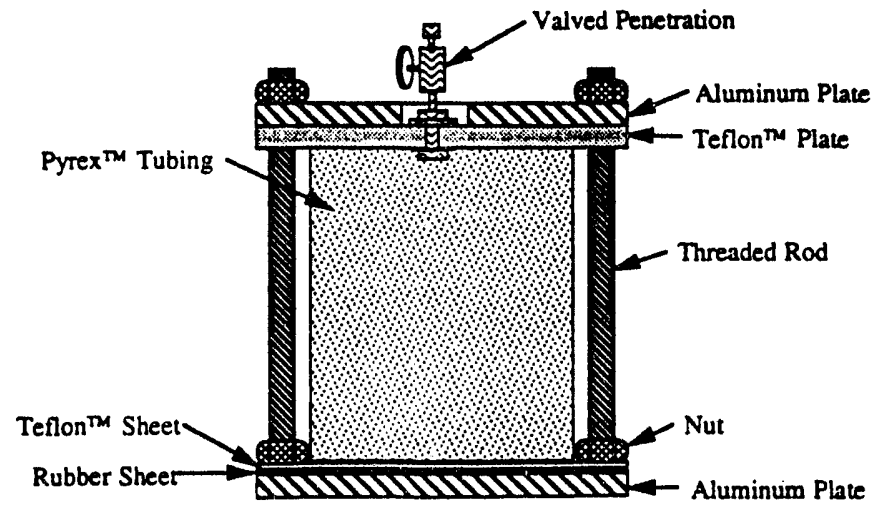

(a)

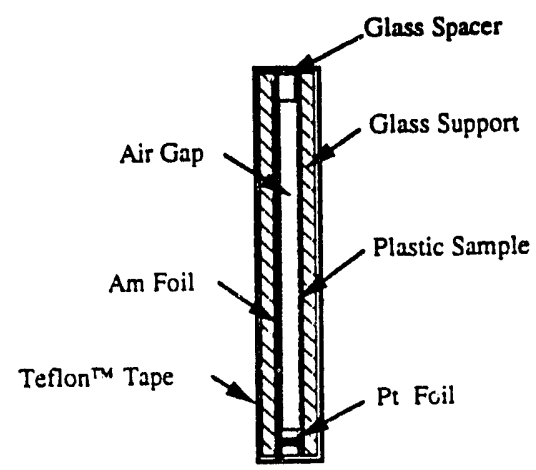

(b)

Figure 1 Irradiation vessel (a) and alpha-particle plasticlrubber material configuration (b) 


\section{RESULTS}

Experiment duration was approximately two months. Gas samples were taken at approximately $1,2,3,4,6$, and 8 weeks. The material was not homogeneously irradiated, due to the high-LET nature of the incident radiation. The dose rate in the thin surface layer defined by the range of the alpha particle was $2 \times 10^{5} \mathrm{rad} / \mathrm{h}$. The average dose rate was much lower, since the thicknesses of the materials used were significantly greater than the range of the alpha particle. These rates compare to a maximum value of $8 \times 10^{5} \mathrm{rad} / \mathrm{h}$ and an average rate of 100 $\mathrm{rad} / \mathrm{h}$ expected in TRU waste. The absorbed dose in the surface layer was 11-12 Mrads for the duration of the experiment.

\section{Bulk Changes, Hydrogen and Carbon Dioxide Generation and Weight Change}

The alpha particle irradiation significantly altered the appearance of three of the four materials. A light yellow discoloration was noted for the initially clear polyvinylchloride. Neoprene, initially black, became grayish. Hypalon, initially white, became light brown. Significant embrittlement, although expected at high absorbed dose, was not evident in the two month experiments where we investigated VOC generation.

As expected, hydrogen and carbon dioxide were the predominant gaseous products from all the materials tested. An example plot of the hydrogen and carbon dioxide concentrations versus time is shown in Figure 2 for polyethylene in air. The yields observed for these two gaseous species are summarized in Table I. For the experiments conducted in air, a significant change in the atmosphere was only noted for polyethylene, where up to $20 \%$ of the oxygen initially present was depleted. This depletion was a result of oxygen uptake into the plastic material, which also resulted in weight gain. In the nitrogen-atmosphere experiments, post-test oxygen levels were typically $<0.1 \mathrm{~mol} \%$, but in some experiments were as high as $1 \mathrm{~mol} \%$. This was due to a combination of outgassing, radiolytic processes, and a small amount of leakage

\begin{tabular}{||c|c|c|c||}
\hline \multirow{2}{*}{ Table I. Apparent Radiolytic Yield of Hydrogen and Carbon Dioxide (G-Value) } \\
\hline \multirow{2}{*}{ Material } & Initial Gas Phase & Hydrogen Yield & $\begin{array}{c}\text { Carbon Dioxide } \\
\text { Yield }\end{array}$ \\
\hline \multirow{2}{*}{ Polyvinylchloride } & Air & $2.5 \pm 0.1$ & $4.8 \pm 0.3$ \\
\cline { 2 - 4 } & Nitrogen & $3.0 \pm 0.1$ & $1.8 \pm 0.1$ \\
\cline { 2 - 4 } & Air & $0.81 \pm 0.03$ & $1.2 \pm 0.1$ \\
\hline \multirow{2}{*}{ Neoprene } & Nitrogen & ND & ND \\
\cline { 2 - 4 } & Air & $1.6 \pm 0.1$ & $2.9 \pm 0.1$ \\
\hline \multirow{2}{*}{ Hypalon } & Nitrogen & $0.39 \pm 0.03$ & $1.6 \pm 0.1$ \\
\cline { 2 - 4 } & Air & $0.61 \pm 0.03$ & $0.72 \pm 0.03$ \\
\cline { 2 - 4 } & Nitrogen & $0.56 \pm 0.03$ & $1.0 \pm 0.03$ \\
\hline
\end{tabular}


into the vessel. In andlogous blank experiments where no Am-241 alpha source was present, oxygen levels remained low, $(<0.1$ mole\%).

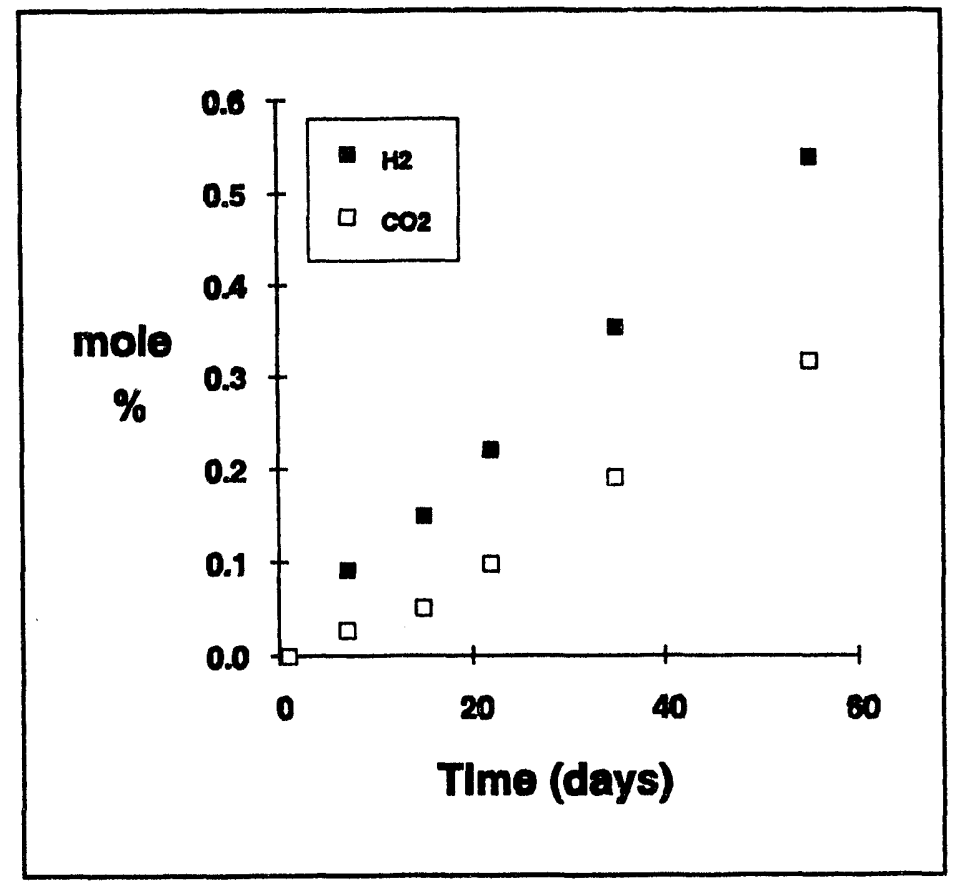

Figure 2. Concentration of hydrogen ( $(\omega)$ and carbon dioxide ( $\square$ ) as a function of time for polyethylene in nitrogen.

Hydrogen formation was predominantly linear with absorbed dose. The yields ranged from 0.4 to 3 molecules $/ 100 \mathrm{eV}$ and decreased in the following order: polyethylene > neoprene > polyvinylchloride $>$ hypalon. Yields observed in the nitrogen and air environments were similar except for neoprene, whose yield in nitrogen was one-quarter of that in air.

Carbon dioxide formation was also linear with absorbed dose. Yields ranged from 0.7 to 4.8 molecules $/ 100 \mathrm{eV}$. Net yields in air decreased in the same order observed for hydrogen formation. In a nitrogen atmosphere, the yields decreased in the order of polyethylene > neoprene $>$ hypalon. For polyethylene and neoprene, the carbon dioxide yield decreased relative to air. In hypalon, however, a slight increase in the carbon dioxide yield was noted. In all experiments with polyethylene and polyvinylchloride we observed small amounts of carbon monoxide (typically $<10 \%$ of the carbon dioxide concentration); none was observed with hypalon and neoprene.

After the experiment terminated, the irradiated plastic and rubber materials were re-weighed to 5 decimal places to determine weight change. Net weight change for all the materials was at the level of tens of milligrams for the two-month exposures. Polyethylene, hypalon, and neoprene gained weight in both the nitrogen and air environment. Overall weight gains were slightly higher when air was present. Polyvinylchloride exhibited weight loss in both environments investigated. Net loss in air was less, by a factor of ten, than that observed in nitrogen gas. 
The VOC radiolytic products are summarized in Table II by organic classification. Alpha irradiation of polyethylene produces detectable quantities of low molecular weight VOCs on the GC-FID. Their concentrations at the end of both the nitrogen and air experiments were, however, below detection limits for the GC-MS (i.e., $1 \mathrm{ppmV}$ for the semi-volatiles). The major products identified in the lower molecular weight VOCs were eight distinguishable $\mathrm{C} 1$ - to $\mathrm{C} 4$ - alkenes and alkanes, with methane and ethylene predominating ( $\sim 50$ to $1500 \mathrm{ppmV}$ ). The major oxygencontaining product was acetone, which was present at comparable concentrations. These were predominantly radiolytic in nature, since significant amounts were not observed in the blank experiments performed. The corresponding yields for these products are 0.03 to 0.6 molecules $/ 100 \mathrm{eV}$.

\begin{tabular}{|c|c|c|c|c|c|c|c|c|}
\hline \multicolumn{9}{|c|}{$\begin{array}{l}\text { Table II. Final Concentration of VOCs in the Alpha Particl } \\
\text { Experiments (ppmV). } \\
\text { ND = not determined, blank = not detected }\end{array}$} \\
\hline \multirow[t]{2}{*}{ Organic } & \multicolumn{2}{|c|}{ Polyethylene } & \multicolumn{2}{|c|}{$\begin{array}{l}\text { Polyvinyl } \\
\text { chloride }\end{array}$} & \multicolumn{2}{|c|}{ Neoprene } & \multicolumn{2}{|c|}{ Hypalon } \\
\hline & Air & $\mathrm{N}_{2}$ & Air & $\mathrm{N}_{2}$ & Air & $\mathrm{N}_{2}$ & Air & $\mathrm{N}_{2}$ \\
\hline Alkane & & & 8.0 & ND & 0.58 & & 1.2 & \\
\hline Alkene & & & 2.7 & ND & & & & \\
\hline Ketone & 7.4 & 2.9 & 16.2 & ND & 13.6 & 13 & 30.1 & 1.6 \\
\hline Aldehyde & & & 5.8 & ND & 0.15 & & 1.0 & \\
\hline Alcohol & & & 3.3 & ND & 0.81 & 0.38 & 2.8 & \\
\hline Chlorinated & & & 4.0 & ND & & 1.3 & & \\
\hline Benzene & & & 1.0 & ND & & & & \\
\hline Nitromethane & & & & ND & & & 0.26 & \\
\hline Acids & & & 0.3 & ND & & & 1.2 & 0.03 \\
\hline
\end{tabular}

Irradiating polyvinylchloride produced the widest diversity of low-molecular-weight products. The GC-FID analyses for irradiation in air are shown in Figure 3. Substantial levels of C2- to C5- alkenes and alkanes were noted with acetone as the predominant product observed. The results of the GC-MS analyses support the GC-FID results. The following VOCs were detected in the final gas phase analysis: chloroethane $(0.56 \mathrm{ppmV})$, pentane $(0.36 \mathrm{ppmV})$, acetone $(14$ ppmV), 2-Me-2-propanol (1.4 ppmV), 1-propanol (0.26 ppmV), butanal (2.4 ppmV), 1chlorobutane $(0.67 \mathrm{ppmV})$, 2-heptene $(0.37 \mathrm{ppmV})$, benzene $(1.1 \mathrm{ppmV})$, heptane $(5.3 \mathrm{ppmV})$, 3-heptene $(0.34 \mathrm{ppmV}), 2$-heptene $(0.5 \mathrm{ppmV}), 1$-butanol $(0.6 \mathrm{ppmV}), 1$-hepatanol $(0.5 \mathrm{ppmV})$, 2-pentanone $(0.2 \mathrm{ppmV})$, pentanal $(1.4 \mathrm{ppmV})$, formic acid $(0.3 \mathrm{ppmV})$, 3-Me-heptane (1.7 $\mathrm{ppmV})$, 3-octene (0.3 ppmV), 3-methylene heptane $(0.8 \mathrm{ppmV})$, octane $(0.4 \mathrm{ppmV}), 2$-octene (0.24 ppmV), 3-Me-heptane (0.24 ppmV), octanol (0.13 ppmV), 2-hexanone ( $0.3 \mathrm{ppmV})$, hexanal 
(1.1 ppmV), 1-chloro-2-butanol (1.1 ppmV), 1-chlorohexane (0.2 ppmV), 4-heptanone (0.01 ppmV), 3-heptanone (1.9 ppmV), 2-heptanone $(0.13 \mathrm{ppmV})$, 3-heptanol $(0.4 \mathrm{ppmV})$, 2-ethylhexanal $(0.9 \mathrm{ppmV})$, and 3-chloromethyl heptane (1.4 ppmV).

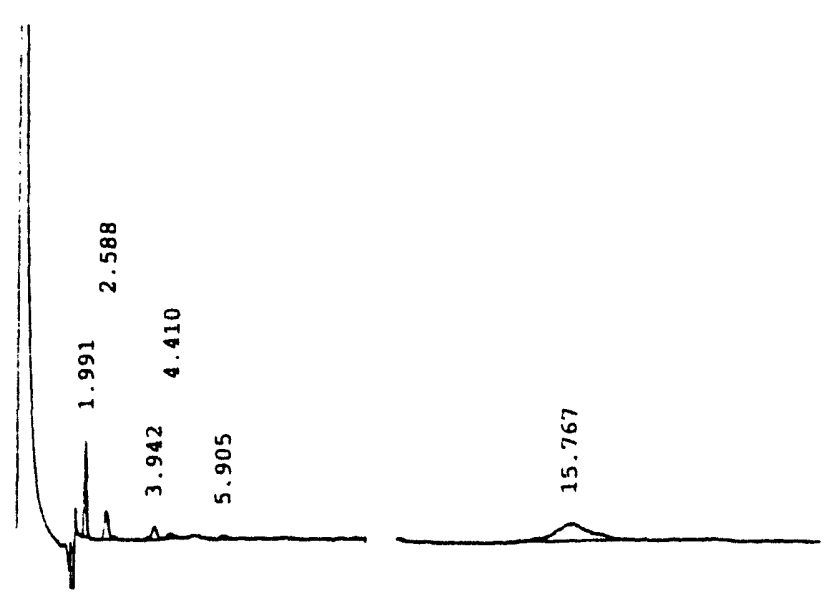

(a)

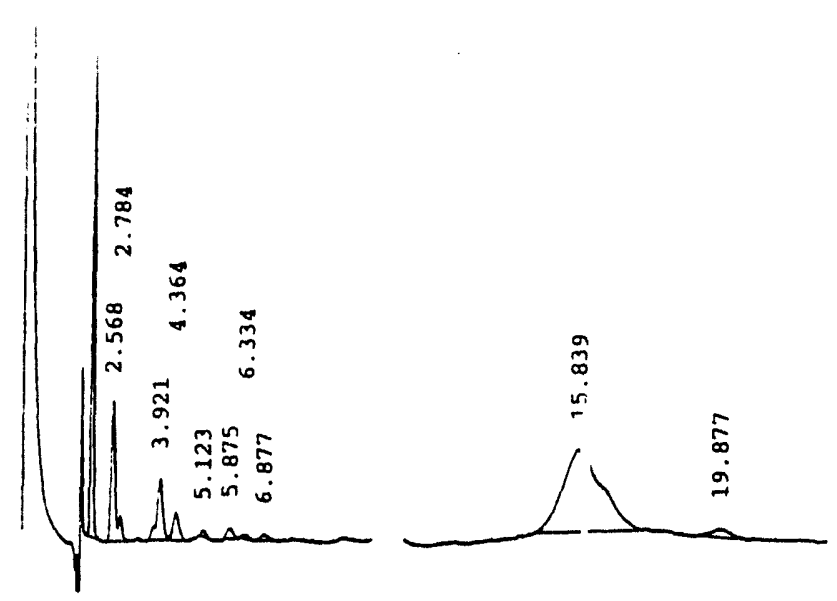

(b)

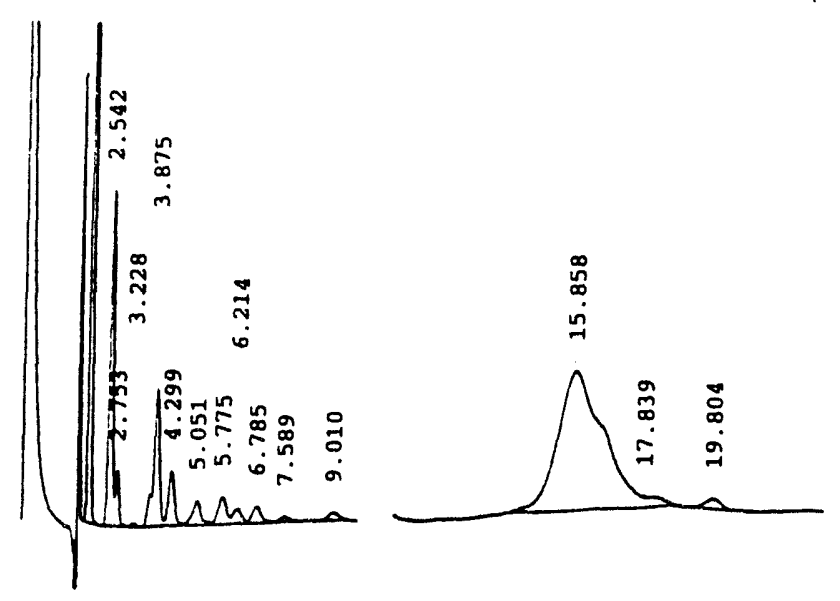

(c)

Figure 3 Gas chromatograms (FID) for light VOCs at 1 week (a), 4 weeks (b), and 8 weeks (c), for polyvinylchloride in air. Approximate retention times are $\mathrm{C} 2=1.9, \mathrm{C} 3=2.7, \mathrm{C} 4=4.3$ and $\mathrm{C} 5=7.6$ minutes. The peak at $\mathrm{t}=15.8$ minutes is acetone.

Irradiating neoprene generated the least amount of VOCs of the materials investigated. In the nitrogen-atmosphere GC-FID, only methane was observed as a product. In air, some methane, ethylene, and acetone were observed, but these concentrations were quite low $(<2 \mathrm{ppmV})$. In the final GC-MS analyses, five VOCs were detected in the gas phase of the experiment containing a nitrogen atmosphere: acetone (13.2 ppmV), methlyene chloride (1.2 ppmV), 2-Me-2propanol $(0.4 \mathrm{ppmV})$, and 4,4 dimethyl-2-pentanone $(0.27 \mathrm{ppmV})$. In air, a greater diversity of products was noted: pentane $(0.2 \mathrm{ppmV})$, acetone (11 ppmV), 2-Me-2-propanol $(0.7 \mathrm{ppmV})$, hexane (0.2 ppmV), 1-propanol (0.06 ppmV), butanal (0.12 ppmV), 2-butanone (1.6 ppmV), 1- 
butanol (0.09 ppmV), 2-pentanone (0.15 ppmV), pentanal (0.03 ppmV), 3-pentanone (0.2 ppmV), octane $(0.09 \mathrm{ppmV})$, 2-hexanone $(0.09 \mathrm{ppmV})$, cyclohexanone $(0.05 \mathrm{ppmV})$, nonane $(0.07$ ppmV), 3-hexanone $(0.12 \mathrm{ppmV})$, 3-heptanone $(0.1 \mathrm{ppmV})$, 2-heptanone $(0.035 \mathrm{ppmV})$, and hexadecane $(0.03 \mathrm{ppmV})$.

Irradiating hypalon resulted in relatively few low-molecular-weight products. Final concentrations in the GC-FID analyses were in the range of $2-5 \mathrm{ppmV}$. No acetone was observed. In the GC-MS semivolatile analysis, only three VOCs were identified in the nitrogenatmosphere experiment: acetone (1.5 ppmV), acetic acid $(0.03 \mathrm{ppmV})$, and di-hydro-furanone $(0.05 \mathrm{ppmV})$. Greater product diversity was noted in the air-containing experiment. Thirty-three products were identified: pentane $(0.43 \mathrm{ppmV})$, acetone $(25.3 \mathrm{ppmV}), 2-\mathrm{Me}-2$-propanol (1.8 ppmV), hexane (0.4 ppmV), 1-propanol $(0.4 \mathrm{ppmV})$, ethyl oxirane $(0.15 \mathrm{ppmV})$, butanal $(0.7$ ppmV), nitro-methane $(0.26 \mathrm{ppmV})$, 2-butanone $(0.5 \mathrm{ppmV}), 1$-butanol $(0.5 \mathrm{ppmV})$, 2-pentanone (0.4 ppmV), 3-pentanone (1.4 ppmV), acetic acid $(0.6 \mathrm{ppmV})$, formic acid $(0.2 \mathrm{ppmV})$, octane (0.06 ppmV), propanoic acid $(0.3 \mathrm{ppmV})$, 2-hexanone $(0.6 \mathrm{ppmV})$, hexanal $(0.3 \mathrm{ppmV})$, cyclopentanone $(0.2 \mathrm{ppmV})$, cylohexanone $(0.04 \mathrm{ppmV})$, butanoic acid $(0.1 \mathrm{ppmV})$, nonane $(0.2$ ppmV), heptanone (0.07 ppmV), 3-hexanone (0.66 ppmV), 3-heptanone (0.5 ppmV), 2-heptanone (0.2 ppmV), 3-Me-1-butanol (0.07 ppmV), 2-methyldecane (0.05 ppmV), 5-hexadione (0.06 ppmV), 4-octanone (0.04 ppmV), dihydro-furanone (0.2 ppmV), and 1-octene-3-one (0.1 ppmV).

\section{SUMMARY OF OBSERVATIONS AND CONCLUSIONS}

The radiolytic degradation and alteration of various plastic and rubber materials has been extensively studied ${ }^{4-8}$. The predominant gaseous products are hydrogen, carbon oxides, and hydrogen chloride from (chlorine-containing organics). Although it was generally recognized that organic species were being generated, the radiolytic production of VOCs, has been largely ignored in past studies ${ }^{7,8}$. The irradiation of WIPP plastic and rubber materials caused the materials to degrade and react with the gas phase present to generate hydrogen, carbon oxides, and VOCs. The extent to which this occurs depends on the material and the gas phase present.

Hydrogen yields, expressed in terms of G-values, were comparable to those observed in gamma and beta studies performed elsewhere. Carbon dioxide was generated in air-containing systems as well as oxygen-depleted systems. Yields were slightly higher than those of hydrogen in all cases, except for polyethylene in a nitrogen atmosphere. Total radiolytic hydrogen and carbon dioxide yields are lower from radiolysis than those expected from gas generation in corrosion and microbial processes ${ }^{9}$.

The wide diversity of VOCs were generated by a combination of direct interactions of ionizing radiation with the materials being irradiated and seccndary reactions in the gas phase from the generated VOCs. In general, the presence of oxygen increased the extent and diversity of the VOC products. This finding follows, given the importance of oxygen in the free radical and ionic reactions that define net radiolytic degradation in both the material matrix and the gas phase.

The generation of VOCs does not appear to be important from the perspective of the gas generation budget in the WIPP or from the perspective of regulatory compliance issues. Total VOC yields were much lower than those observed for hydrogen and carbon oxides. They may 
however, remain of interest to the WIPP for quantifying and meeting regulatory compliance issues, since a number of the VOCs we have detected are RCRA-listed compounds. These compounds include halogenated hydrocarbons (chorine-containing organics), ketones, aldehydes, benzene, and some nitro compounds. Further evaluation of the impacts of these results on the WIPP is the subject of ongoing and future laboratory studies.

\section{ACKNOWLEDGEMENT}

This work was supported by the U. S. Department of Energy, under Contract W31-109-ENG38 as part of the WIPP Gas Generation Program, as directed by Sandia National Laboratories. The authors wish to thank the Analytical Chemistry Laboratory at Argonne National Laboratory for performing the VOC analyses reported.

\section{REFERENCES}

1. L.H. Brush, "Test Plan for Laboratory and Modeling Studies of Repository and Radionuclide Chemistry for the Waste Isolation Pilot Plant". Sandia National Laboratories SAND90-0266 (1990).

2. A.R. Lappin and R. Hunter, Eds., "Systems Analysis, Long-Term Radionuclide Transport, and Dose Assessments, Waste Isolation Pilot Plant (WIPP), Southeastern New Mexico". Sandia National Laboratories Report SAND89-0462 (1989).

3. D.T. Reed, "Radiolytic Gas Production in the Alpha Particle Degradation of Plastics," in Proceedings of Waste Management 92, 1081-1086 (1992).

4. J.W.T. Spinks and R.J. Woods, Introduction to Radiation Chemistry, Chapter 9, John Wiley and Sons, New York (1976).

5. A. Charlesby, "Radiation Chemistry of Polymers," Chap. 15 in Radiation Chemistry, Farhatziz and M.A.J. Rodgers, Eds., VCH Publishers Inc., New York, pp. 451-475 (1987).

6. A. Chapiro, Radiation Chemistry of Polymeric Systems, Interscience Publishers, New York (1962).

7. M. Dole and D.M. Bodily, "Reactive Intermediate in the Radiation Chemistry of Polyethylene," Adv. Chem. Series, 66, 31-43 (1967).

8. S. T. Kosiewicz, "Gas Generation from Organic Transuranic Wastes. I. Alpha Radiolysis at Atmospheric Pressure," Nuc. Tech., 54, 92 (1981).

9. L.H. Brush, M.A. Molecke, R.E. Westerman, A.J. Francis, J.B. Gillow, R.H. Vreeland and D.T. Reed, "Laboratory Studies of Gas Generation for the Waste Isolation Pilot Plant," Proceedings of Symposium on Scientific Basis for Nuclear Waste Management XVI, 294 (1992) 335-342. 

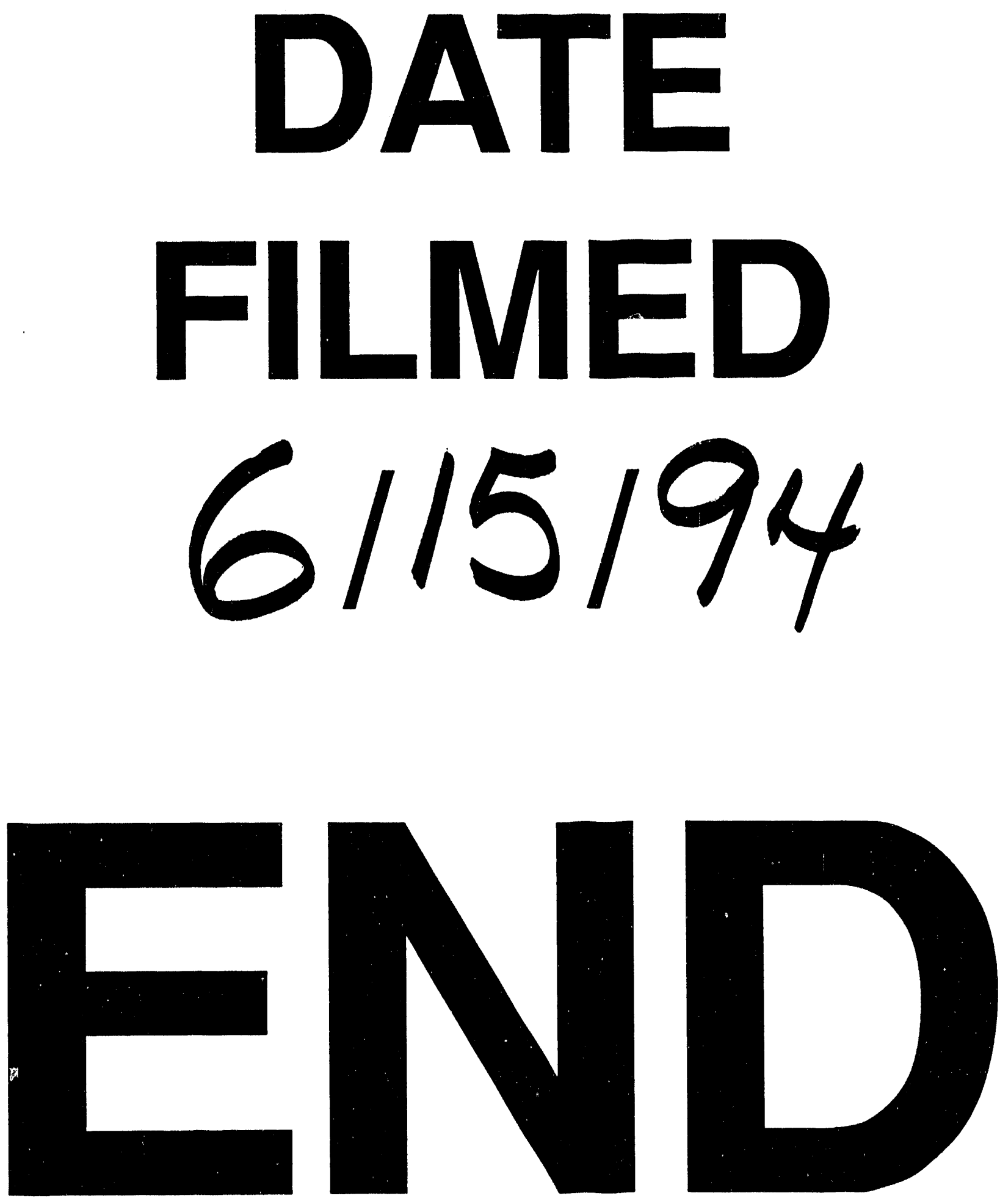
